\title{
Serum selenium status of HIV-infected children on care and treatment in Enugu, Nigeria
}

\author{
A C Ubesie, ${ }^{1,2}$ MBBS, MPH, FMCPaed, FWCAP; B C Ibe, ${ }^{1,2}$ MBBS, FMCPaed, FWCAP; I J Emodi, ${ }^{1,2}$ MBBS, FMCPaed, FWCAP; \\ K K Iloh, ${ }^{2}$ MBBS, FMCPaed, FWCAP \\ ${ }^{1}$ Department of Paediatrics, College of Medicine, University of Nigeria, Nsukka, Nigeria \\ ${ }^{2}$ Department of Paediatrics, College of Medicine, University of Nigeria Teaching Hospital, Ituku/Ozalla, Enugu, Nigeria
}

Corresponding author: A C Ubesie (agozie.ubesie@unn.edu.ng)

\begin{abstract}
Objective. To compare the selenium status of HIV-infected and HIV-uninfected children.
Methods. This was a hospital-based comparative study using a structured questionnaire in the quantitative research domain at the University of Nigeria Teaching Hospital, Ituku/Ozalla, Enugu, Nigeria. Seventy-four HIV-infected children were compared with 74 nonHIV-infected children ( 35 males and 39 females in each group). The outcome measure was the selenium status of the study participants. Results. The mean (standard deviation (SD)) weight-for-height $z$-score among the subjects was -0.18 (1.53) compared with 0.05 (1.68) among the controls $(p=0.457)$. The mean (SD) height-for-age $z$-score among the subjects was -1.16 (1.44) compared with 0.06 (1.06) among the controls $(p<0.001)$. Eighteen subjects $(24.3 \%)$ compared with eight controls $(11.4 \%)$ were selenium deficient (odds ratio 2.49 ; $95 \%$ confidence interval $1.00-6.18 ; p=0.044$ ). Median CD4 counts of selenium-deficient and non-deficient subjects were 765.5 (range 409 1489 ) and 694.0 (range 85 - 2196 ) cells/ $\mu \mathrm{L}$, respectively ( $p=0.321$ ). The proportions of selenium deficiency were $26.4 \%$ and $22.2 \%$ in the highly active antiretroviral therapy (HAART) and pre-HAART groups, respectively $(p=0.565)$.

Conclusion. There was a significant difference in the proportion of HIV-infected children who were selenium deficient compared with their uninfected counterparts.
\end{abstract}

S Afr J Child Health 2017;11(1):21-25. DOI:10.7196/SAJCH.2017.v11i1.1134

Worldwide, an estimated 2.5 million children under 15 years of age are living with HIV, and more than 2.3 million of them live in subSaharan Africa. ${ }^{[1]}$ Infections and malnutrition have been shown to be associated with increased HIV mortality. ${ }^{[2]}$ HIV-related malnutrition involves both micro- and macronutrient deficiencies. ${ }^{[3]}$ There is a compelling association of micronutrient deficiencies in HIV-infection with immune deficiency, rapid disease progression and mortality. ${ }^{[4]}$ Micronutrient supplements can delay HIV disease progression and reduce mortality in HIV-infected persons not receiving highly-active antiretroviral therapy (HAART). ${ }^{[5]}$

Although the use of HAART has revolutionised the management of HIV infection, micronutrient deficiencies still occur among HIV-infected patients on HAART. ${ }^{[6]}$ The provision of simple, inexpensive micronutrient supplements as an adjunct to HAART may therefore have several cellular and clinical benefits, such as a reduction in mitochondrial toxicity and oxidative stress and an improvement in immune reconstitution. ${ }^{[5]}$ One such micronutrient is selenium, an essential trace element with antioxidant properties. ${ }^{[7]}$ In humans and animals, selenium increases immune function and is required for growth and reproduction ${ }^{[8]}$ It also exerts antiviral activities by inhibiting reverse transcriptase enzyme in RNA-virus-infected animals. ${ }^{[9,10]}$ Supplemental selenium can potentially prevent the replication of HIV and retard the development of AIDS in newly infected subjects. ${ }^{[9]}$ Ensuring selenium sufficiency among HIVinfected children, especially in settings with a high burden of malnutrition, may improve survival. However, studies that have evaluated the prevalence of selenium deficiency among HIV-infected children are limited. This study set out to evaluate the prevalence of selenium deficiency among HIVinfected children compared with uninfected controls at the University of Nigeria Teaching Hospital (UNTH), Enugu State.

\section{Study area and design}

This was a hospital-based comparative study of selenium in HIVinfected and HIV-uninfected children carried out between October
2013 and August 2014 at the UNTH. The hospital serves as a referral centre to primary and secondary healthcare facilities within and outside south-eastern Nigeria. It is among the first generation of tertiary hospital facilities in the country. HIV-infected children are managed at the paediatric HIV clinic, which runs once a week.

\section{Study population}

The subjects were HIV-infected children aged 6 - 180 months (15 years) enrolled between October 2013 and February 2014. The control group was non-HIV-infected children, matched for age, sex and socioeconomic status, who were recruited from the children's outpatient clinic of the teaching hospital. Socioeconomic index scores were assigned to the occupations and educational attainments of the parents or caregivers of subjects and controls using the Oyedeji socioeconomic classification scheme, which grades subjects from I to $\mathrm{V}{ }^{[11]}$ The socioeconomic classification for each study participant was obtained by finding the mean score of his or her parents. If either of the parents was dead, the score of the surviving parent was used, and if both parents were dead, the score of the caregiver was used. Classes I and II were regarded as upper social class, III as middle and IV and $\mathrm{V}$ as lower social class.

\section{Inclusion criteria}

The subjects were confirmed HIV-infected children aged 6 - 180 months (15 years), and the controls were HIV-uninfected children on follow-up visits at the children's outpatient clinic matched for age, sex and socioeconomic status with the subjects.

\section{Exclusion criteria}

Children aged $\geq 7$ years who refused to assent to the study or whose caregivers refused consent, as well as those with a history of micronutrient supplementation in the past 3 months, were excluded. 


\section{Consent}

Thumb-printed and/or signed informed consent was obtained from the parents or caregivers, while assent was obtained from study participants aged $\geq 7$ years.

\section{Recruitment of study participants}

Children who met the inclusion criteria were enrolled consecutively until the desired sample size for the subjects and controls was achieved. Seventy-four HIV-infected children served as the subjects, while nonHIV-infected children matched for age, sex and socioeconomic status served as the controls. A structured questionnaire was used to collect the following data from the subjects and controls: age in months, date of birth, date of interview, and the highest educational attainment and occupation of parents or caregivers. Data on HAART regimen and duration of treatment were retrieved from the medical records of the HIV-infected children. The controls were screened for the presence of HIV antibodies using the national algorithm for HIV testing.

The study participants were examined for the presence of any clinical signs of illness. An infant weighing scale (Hospibrand ZT-120, $\mathrm{UK}$ ) was used to measure the weights of children under 2 years to the nearest $0.1 \mathrm{~kg}$, while a standing scale was used for children aged 2 years and above. Weight measuring instruments were set to zero point before use and standardised at weekly intervals using known weights. Length was measured using an infantometer (Seca, Germany) for children under 2 years while height was measured for children 2 years and above using a stadiometer to the nearest $0.1 \mathrm{~cm}$.

\section{Nutritional assessment}

Height-for-age $z$-score (HAZ), weight-forheight $z$-score (WHZ) and body mass indexfor-age $z$-score (BMIZ) values were calculated using the 2005 World Health Organization (WHO) AnthroPlus version 1.0.4 software calculator (Switzerland). ${ }^{[12]}$ Acute malnutrition (wasting) was defined as WHZ and BMI $z$-scores $\leq-2$ while chronic malnutrition (stunting) was defined as $\mathrm{HAZ} \leq-2 .^{[13]}$

\section{Laboratory tests}

Two aliquots of $5 \mathrm{~mL}$ of blood were collected from the antecubital fossa of the subjects. The first aliquot for CD4 estimation was collected in an ethylenediaminetetraacetic acid (EDTA) bottle. The second aliquot for selenium was collected in plain bottles. Similarly, a $5 \mathrm{~mL}$ aliquot of blood was collected in plain bottles from the antecubital fossa of controls for selenium estimations. The blood samples for CD4 estimation were analysed using the Partec CyFlow machine (Germany). Serum selenium was measured by the spectrophotometric method using the Safranin O method. The following are recommended normal selenium levels: $:^{[14,15]}$

- $<18$ months: $30-50 \mu \mathrm{g} / \mathrm{L}(0.38-0.63$ $\mu \mathrm{mol} / \mathrm{L})$

- 18 months - 4 years: 45 - $90 \mu \mathrm{g} / \mathrm{L}$ (0.57 $1.14 \mu \mathrm{mol} / \mathrm{L})$

- 5 - 16 years: 55 - $115 \mu \mathrm{g} / \mathrm{L}(0.70-1.46 \mu \mathrm{mol} / \mathrm{L})$ - adults (>16 years): 70 - $130 \mu \mathrm{g} / \mathrm{L}(0.89$ $1.65 \mu \mathrm{mol})$.

In this study, therefore, selenium deficiency was defined as follows:

- $<18$ months: $<30 \mu \mathrm{g} / \mathrm{L}(0.38 \mu \mathrm{mol} / \mathrm{L})$

- 18 months -4 years: $<45 \mu \mathrm{g} / \mathrm{L}(0.57 \mu \mathrm{mol} / \mathrm{L})$

- 5 - 15 years: $<55 \mu \mathrm{g} / \mathrm{L}(0.70 \mu \mathrm{mol} / \mathrm{L})$.

\section{Data analysis}

Data analysis was carried out using the Statistical Package for Social Sciences (SPSS) version 19.0 (IBM Corp., USA). The $\chi^{2}$ and Fisher's exact tests were used to test for the significant association of categorical variables. Fisher's exact test was used if the expected number in a cell of a two-by-two table was less than five, and Yates' correction if a cell contained zero. The quantitative data were tested for normality using the ShapiroWilk normality test. A Student $t$-test was used to compare the mean WAZ and HAZ between the subjects and controls. MannWhitney $U$ - and Kruskal-Wallis tests were used to test for a significant association between CD4 count/selenium levels and independent variables. The odds ratio (ORs) of selenium deficiency between subjects and controls was calculated, and 95\% confidence interval (CIs) reported. All analyses were done at the $5 \%$ level of significance and $p<0.05$ was considered statistically significant.

\section{Ethical approval}

The hospital's Health Research and Ethics Committee approved the study (ref. no. NHREC/05/01/2008B-FWA00002458IRB00002323).

\section{Results}

\section{Study participants}

One hundred and forty-eight participants ( 74 subjects, 74 controls) were included in the study. The sociodemographic characteristics of the study population are shown in Table 1. A blood sample for selenium analysis was available in 74 subjects and 70 controls. The median ages of the subjects and controls were 94.8 and 84.0 months, respectively (range 7 180 months). Forty (54.1\%) of the subjects and $37(50.0 \%)$ of the controls were from the middle social class $(p=0.777)$.

\section{CD4 counts and antiretroviral (ARV) regimen}

The median CD4 count of the subjects was 741.5 (interquartile range (IQR) 472.0 - 1

Table 1. Sociodemographic characteristics of the study population

\begin{tabular}{llllll}
\hline $\begin{array}{l}\text { Sociodemographic } \\
\text { characteristics }\end{array}$ & $\begin{array}{l}\text { Subjects, } \\
\boldsymbol{n}(\%)\end{array}$ & $\begin{array}{l}\text { Controls, } \\
\boldsymbol{n}(\%)\end{array}$ & $\chi^{2}$ & df & $p$-value \\
\hline Age group (years) & $25(33.8)$ & $24(32.4)$ & 0.147 & 2 & 0.923 \\
$0.5-5.0$ & $32(43.2)$ & $31(41.9)$ & & \\
$5.1-10.0$ & $17(23.0)$ & $19(25.7)$ & & \\
$10.1-15.0$ & $35(47.3)$ & $35(47.3)$ & 0.0 & 1 & \\
Sex & $39(52.7)$ & $39(52.7)$ & & \\
Male & & & & \\
Female & $10(13.5)$ & $13(17.6)$ & 0.508 & 2 \\
Socioeconomic class & $40(54.1)$ & $37(50.0)$ & & \\
Upper & $24(32.4)$ & $24(32.4)$ & &
\end{tabular}

Table 2. Comparison of the mean anthropometric parameters of the subjects and controls

\begin{tabular}{lllll}
\hline $\begin{array}{l}\text { Anthropometric } \\
\text { parameters }\end{array}$ & $\begin{array}{l}\text { Subjects, } \\
\text { mean (SD) }\end{array}$ & $\begin{array}{l}\text { Controls, } \\
\text { mean (SD) }\end{array}$ & $\boldsymbol{t}$-value & $\boldsymbol{p}$-value \\
\hline Weight $(\mathrm{kg})$ & $24.3(9.6)$ & $26.1(13.8)$ & -0.91 & 0.364 \\
Height $(\mathrm{cm})$ & $118.4(21.6)$ & $121.5(25.0)$ & -0.80 & 0.426 \\
WHZ & $0.2(1.5)$ & $-0.1(1.7)$ & 0.718 & 0.457 \\
HAZ & $-1.2(1.4)$ & $0.1(1.1)$ & -5.677 & $<0.001$ \\
BMIZ & $-1.5(15.3)$ & $-0.2(1.9)$ & -0.706 & 0.481
\end{tabular}


202.8 cells $/ \mu \mathrm{L}$. Fifty-six of the 74 subjects (75.7\%) were on HAART, while 10 (17.9\%) of the 56 children on HAART had been switched to a second-line regimen. Zidovudine (AZT), Lamivudine (3TC) and Nevirapine (NVP) were the first-line combination therapy in 46 (82.1\%) of the 56 children on HAART.

\section{Nutritional status}

The mean (standard deviation (SD)) weight and height of the subjects and controls were $24.3(9.5)$ v. $26.1(13.8) \mathrm{kg}$, and 118.4 (21.6) v. $121.5(25.0) \mathrm{cm}$, respectively (Table 2$)$. The mean WHZ among the subjects was -0.2 (1.5) compared with -0.1 (1.7) among the controls $(p=0.457)$. The mean HAZ among the subjects were - 1.2 (1.4) compared with 0.1 (1.1) among the controls $(p<0.001)$ (Table 2).

Five $(6.8 \%)$ of the 74 subjects and 5 (6.8\%) of the 74 controls had acute malnutrition (Fisher's exact test, $p=1$ ). Conversely, 18 (24.3\%) subjects compared with none of the controls had chronic malnutrition $(p<0.001)$.

\section{Serum selenium levels of study participants}

The mean (SD) serum level of selenium among the subjects was 82.1 (6.3) $\mu \mathrm{g} / \mathrm{L}$ compared with 97.3 (7.1) $\mu \mathrm{g} / \mathrm{L}$ among the controls $(p=0.11)$. The median serum selenium levels for subjects and controls were 76.9 (IQR 50.8 - 98.1) $\mu \mathrm{g} / \mathrm{L}$ and 83.30 (IQR 61.6 - 113.8) $\mu \mathrm{g} / \mathrm{L}(p=0.085)$.

\section{Selenium deficiency}

Eighteen (24.3\%) of the 74 subjects compared with eight (11.4\%) of 70 controls were selenium deficient $(p=0.044)$. The OR of selenium deficiency among the subjects was 2.49 times higher among the subjects than the controls (OR 2.49; 95\% CI 1.00 $6.18 ; z=1.9 ; p=0.049$ ).

\section{Age and serum selenium levels}

The median ages of selenium-deficient and non-deficient study participants were 92.4 (IQR 62.4 - 123.6) and 90 (IQR 49.2 - 124.8) months, respectively $(p=0.728)$. Seven $(28.0 \%)$ of 25 subjects aged 6 - 60 months were selenium deficient ( $p=0.863$ ). Six (20.7\%) of 29 children aged 61 - 120 months were selenium deficient among the controls $(p=0.093)$.

\section{Sex and serum selenium levels}

Twelve (34.3\%) of 35 males compared with $6(15.4 \%)$ of 39 females were selenium deficient among the subjects $(p=0.058)$. Six (18.7\%) of 32 males compared with 2 (5.3\%) of 38 females were selenium-deficient among the controls $(p=0.077)$ (Table 3).

\section{Risk factors for selenium deficiency} Nutritional status

One (20\%) of the five acutely malnourished subjects was selenium deficient, compared

Table 3. Distribution of selenium-deficient study participants by sex

\begin{tabular}{llllll}
\hline & \multicolumn{2}{c}{ HIV-infected $(n=74)^{*}$} & & \multicolumn{2}{c}{ HIV-uninfected $(n=70)^{\dagger}$} \\
& Yes $(n \%)$ & No $(n \%)$ & & Yes $(n \%)$ & No $(n \%)$ \\
\hline Sex & & & & \\
$\quad$ Male & $12(34.3)$ & $23(65.7)$ & & $6(18.7)$ & $26(81.3)$ \\
$\quad$ Female & $6(15.4)$ & $33(84.6)$ & & $2(5.3)$ & $36(94.7)$ \\
Total & $18(22.5)$ & $52(77.5)$ & & $8(11.4)$ & $62(88.6)$ \\
${ }^{*}\left(\chi^{2}=3.58, \mathrm{df}=1, p=0.058\right)$ & & & \\
${ }^{\dagger}\left(\chi^{2}=3.12, \mathrm{df}=1, p=0.077\right)$ & & & &
\end{tabular}

with 17 (24.6\%) of 69 without acute malnu trition (Fisher's exact test, $p=1.0$ ). The mean WHZ and BMIZ among the seleniumdeficient subjects were $0.2(0.8)$ and -6.9 (31.0), respectively, compared with -0.3 (1.4) and $0.2(1.3)$ among non-deficient subjects. Four $(22.2 \%)$ of the 18 subjects with chronic malnutrition compared with 14 (25\%) of 56 subjects without chronic malnutrition were selenium deficient (Fisher's exact test, $p=1$ ). The mean HAZ among selenium-deficient subjects was -1.06 (1.61), compared with -1.09 (1.36) among the non-selenium-deficient subjects $(p=0.943)$.

\section{CD4 and HAART}

The median CD4 counts of the 18 seleniumdeficient and 56 non-deficient subjects were 765.5 (range 409 - 1489 ) and 694.0 (range 85 - 2 196) cells/ $\mu \mathrm{L}$ of blood, respectively $(p=0.321)$. Fourteen $(26.4 \%)$ of 53 subjects on HAART compared with four $(22.2 \%)$ of 21 ART-naive subjects and eight (11.4\%) of 70 controls were selenium deficient $(p=0.086)$. There was no statistically significant difference between HAART and pre-HAART subjects who were selenium deficient $(p=0.565)$. The mean (SD) duration of HAART for seleniumdeficient subjects was 41.1 (30.8) months, compared with 43.4 (29.9) months among selenium-sufficient subjects ( $p=0.807)$.

\section{Discussion}

This study showed that a significantly higher proportion of HIV-infected children compared with their non-infected counterparts were selenium deficient. The OR of selenium deficiency was 2.5 times higher among the subjects than the controls. Lower serum selenium levels among HIV-infected indivi duals have been linked to excessive utilisation of selenoproteins by the virus. ${ }^{[16]}$ It is this increased utilisation of the selenoproteins in HIV-infected individuals that results in selenium depletion. A study in Ife, south-west Nigeria, also reported a significantly higher rate of selenium deficiency among HIV-infected children compared with the uninfected controls who were matched for age and sex with the subjects. ${ }^{[17]}$ However, the reported rates of selenium deficiency among the subjects and controls were higher than the findings in the present study. The group in the Ife, Nigeria, study included only ARV-naive subjects, and this may explain their reported higher proportion of selenium deficiency among HIVinfected children. The present study included both ARV-naive subjects and subjects on HAART. It is possible that HAART would have slowed down viral replications, reduced the need for selenoprotein synthesis and ultimately lowered the proportion of selenium-deficient subjects.

In contrast to the present study, Henderson et al. ${ }^{[18]}$ reported lower selenium deficiency rates among $38 \mathrm{HIV}$-infected and -uninfected children in the USA. The lower rates found by Henderson et al. ${ }^{[18]}$ can be explained by their small sample size of 38 subjects ( 28 HIV-infected and $10 \mathrm{HIV}$-uninfected), which limits the generalisability of their findings. The present study had a larger sample size of 148. Additionally, Henderson et al. ${ }^{[18]}$ conducted their study in a country where it has been shown that adequate amounts of selenium are consumed, with an average daily intake from foods for those aged $\geq 2$ years reaching $108.5 \mu \mathrm{g}$. Bunupuradah et al. ${ }^{[20]}$ reported no deficiency in baseline selenium levels among 141 HIV-infected Thai children aged 1 - 12 years. The reason for their reported zero prevalence can be explained by their very low cut-off definition for selenium deficiency $(<0.1 \mu \mathrm{mol} / \mathrm{L}$ or $8 \mu \mathrm{g} / \mathrm{L})$ in these children.

\section{Age and sex}

The difference in the proportion of selenium deficiency among the three age groups of subjects in this study was not statistically significant. This agrees with the findings of Kouna et al. ${ }^{[21]}$ in their study of 318 children aged 7 - 10 years. A possible explanation for this lack of significant difference may be that a wide variety of foods are rich in selenium, including seafoods, organ meats, grains and dairy products, which are consumed across age groups. ${ }^{[17,24]}$ The findings of the northeast Thailand study by Krittaphol et al., ${ }^{[22]}$ however, disagree with those of the present 
study. The authors reported that children under 9 years of age had a significantly lower mean serum selenium concentration than those over 9 years of age. The basis for dichotomising the children into under and over 9 by the authors was rather arbitrary and unclear.

Among the subjects and controls, the proportion of selenium deficiency was not significantly different between the sexes. There are conflicting reports in the literature regarding selenium levels and sex. Jones et al. ${ }^{[23]}$ and Kouna et al. ${ }^{[21]}$ reported no significant difference in the proportion of selenium deficiency between the sexes, which finding agrees with the present study. Rousseau et al., ${ }^{[24]}$ however, reported significantly lower selenium in males than females among $30 \mathrm{HIV}$-infected individuals. Safaralizadeh ${ }^{[25]}$ also reported that the mean serum selenium levels were significantly lower in male than female children aged 1 - 16 years. Studies reporting lower selenium among males have failed to offer plausible explanations for the disparity. In contrast, Amare et al. ${ }^{[26]}$ reported a higher rate of selenium deficiency in females than males. Krittaphol et al. ${ }^{[2]}$ also reported that females had a significantly lower mean serum selenium concentration than males in their sample. Studies reporting lower selenium values among females have postulated a sex-linked hormonal influence onthe serum level of selenium. ${ }^{[25,26]}$

\section{Nutritional status}

There was no significant difference in the proportion of subjects with acute and chronic malnutrition who were selenium deficient. Nhien et al. ${ }^{[27]}$ reported no significant difference in serum concentration of selenium with regard to underweight, stunting and wasting. Amare et al. ${ }^{[28]}$ also reported no significant correlation between the levels of selenium and the anthropometric variables of schoolchildren. These findings suggest that selenium status in children is independent of their macronutrient status. This finding is not surprising because micronutrient deficiencies, or hidden hunger, remain a public health challenge among apparently healthy children, especially in developing countries.

\section{Immunological status and HAART}

There was no significant difference in the median CD4 count of selenium-deficient and non-deficient subjects in this study. Although Anyabolu et al. ${ }^{[17]}$ in the Ife study reported higher mean serum selenium levels in subjects with a CD4 count of $\geq 350$ cells/ $\mu \mathrm{L}$ compared with those with $<350$ cells $/ \mu \mathrm{L}$, they failed to explain the rationale for grouping these children based on the CD4 counts of $\geq 350$ and $<350$ cells $/ \mu \mathrm{L}$. The difference in the approach to statistical analysis of CD4 and serum selenium between their study and the present study makes it difficult to draw a meaningful comparison between the two studies.

The median serum selenium level among subjects on HAART did not differ significantly from that of those who were yet to commence HAART. There was also no significant difference in the proportion of subjects on HAART who were selenium deficient compared with the pre-ART subjects in this study. Similarly, when the proportion of selenium deficiency in the three groups of HAART, pre-HAART and controls was compared, no significant difference was found. To the best of the authors' knowledge, this is the first study that compares selenium status between HIV-infected children on HAART and those who are not. Akinola et al ${ }^{[6]}$ in a study involving HIV-infected adults reported no significant difference in the serum levels of selenium of their subjects on HAART and those who were yet to commence HAART, which agrees with the finding of the present study.

\section{Study limitations}

The study did not assess dietary intakes of selenium among the study participants. The exclusion of study participants based on a history of micronutrient supplements was inadequate, since there could have been recall bias.

\section{Conclusion}

Although selenium deficiency was significantly higher among the subjects than controls, no significant difference was noted between the sexes. Nutritional status, CD4 cell count and use of HAART were not significantly associated with selenium levels in this study.

1. Heeren GA, Jemmott JB, Sidloyi L, Ngwale Z, Tyler JC. Disclosure of HIV diagnosis to HIV-infected children in South Africa: Focus groups for intervention development. Vulnerable Child Youth Study 2012;7(1):47-54. https://doi.org/10.1080/17450128.2012.656733

2. Munyagwa M, Baisley K, Levin J, Brian M, Grosskurth H, Maher D. Mortality of HIV infected and uninfected children in a longitudinal cohort in rural southwest Uganda during 8 years of follow-up. Trop Med Int Health 2012;17(7):836843. https://doi.org/10.1111/j.1365-3156.2012.03000.x

3. Ndeezi G, Tyllerskar T, Ndugwa CM, Tumwine JK. Effect of multiple micronutrient supplementation on survival of HIV-infected children in Uganda: A randomized, controlled trial. J Int AIDS Soc 2010;13:1-9. https:// doi.org/10.1186/1758-2652-13-18

4. Singhal N. A clinical review of micronutrients in HIV infection. J Int Assoc Provid AIDS Care 2002;1(2):63-75. https://doi.org/10.1089/apc.1998.12.249

5. Drain PK, Kupka R, Mugusi F, Fawzi WW. Micronutrients in HIV-positive persons receiving highly active antiretroviral therapy. Am J Clin Nutr 2007;85(2):333-345. https://doi.org/10.1097/qad.0b013e32826fb6c7

6. Akinola FF, Akinjinmi AA, Oguntibeju OO. Effect of combined antiretroviral therapy on selected trace elements and $\mathrm{CD} 4^{+} \mathrm{T}$-cell count in HIV-positive persons in an African setting. J AIDS Clinic Res 2012;3(10):185. https://doi. org/10.4172/2155-6113.1000185

7. Townsend A, Featherstone A, Chéry CC, Vanhaecke F, Kirby J, Krikowa F. Increased selenium concentration in seronorm trace elements serum (level 2). Clin Chem 2004;50(8):1481-1482. https://doi.org/10.1373/clinchem.2004.034579

8. Fan AM, Kizer KW. Selenium: Nutritional, toxicologic, and clinical aspects. Western J Med 1990;153(2):160-167.

9. Schrauzer GN, Sacher J. Selenium in the maintenance and therapy of HIVinfected patients. Chem Biol Interact 1994;91(2-3):199-205. https://doi. org/10.1016/0009-2797(94)90040-x

10. Stone CA, Kawai K, Kupka R, Fawzi WW. The role of selenium in HIV infection. Nutr Rev 2010;68(11):671-681. https://doi.org/10.1111/j.17534887.2010.00337.x

11. Oyedeji GA. Socio-economic and cultural background of hospitalized children in Ilesha. Nig J Paediatr 1985;12(4):111-117.

12. World Health Organization. WHO Anthro (version 3.2.2) and macros. Geneva: WHO, 2011. http://www.who.int/childgrowth/software/en/ (accessed 26 February 2013).

13. World Health Organization Multicentre Growth Reference Study Group. WHO Child Growth Standards: Length/height-for-age, Weight-for-age, Weightfor-length, Weight-for-height and Body Mass index-for-age: Methods and Development. Geneva: WHO, 2006.

14. Supra-regional Assay Service Trace Element Laboratories. In: Walker AW, ed. Clinical and Analytical Handbook. 4th ed. Guildford, UK: Department of Clinical Biochemistry, Royal Surrey County Hospital, 2006

15. National Health Service Trust. Recommended protocol for monitoring copper, zinc and selenium. 2011. http://www.cityassays.org.uk/downloads/ CopperZincMagnesium\%201.01.pdf (accessed 12 November 2013).

16. Taylor EW, Cox AG, Zhao L, et al. Nutrition, HIV, and drug abuse: The molecular basis of unique role for selenium. J Acquir Immune Defic Syndr 2000;25(1):S53-S61.

17. Anyabolu HC, Adejuyigbe EA, Adeodu OO. Serum micronutrient status of HAART-naive, HIV-infected children in south-western Nigeria: A case controlled study. AIDS Res Treat 2014;2014:351043. https://doi. org/10.1155/2014/351043

18. Henderson RA, Talusan K, Hutton N, Yolken RH, Caballero B. Serum and plasma markers of nutritional status in children infected with the human immunodeficiency virus. J Am Diet Assoc 1997;97(12):1377-1381. https://doi. org/10.1016/s0002-8223(97)00333-7

19. National Institutes of Health. Selenium: Dietary supplement fact sheets. 2013. http://ods.od.nih.gov/factsheets/Selenium-HealthProfessional/ (accessed 7 December 2014)

20. Bunupuradah T, Ubolyam S, Hansudewechakul R, Kosalaraksa P, Ngampiyaskul C, Kanjanavanit S. Correlation of selenium and zinc levels to antiretroviral treatment outcomes in Thai HIV-infected children without severe HIV symptoms. Eur J Clin Nutr 2012;66(8):900-905. https://doi.org/10.1038/ ejcn.2012.57

21. Kouna P, Mashavave G, Kandawasvika GQ, et al. Serum selenium levels and nutritional status of school children from an HIV prevention programme in Zimbabwe. J Trop Dis Pub Health 2014;2:134. https://doi.org/10.4172/2329891X.1000134

22. Krittaphol W, Bailey KB, Pongcharoen T, Winichagoon P, Thomson C, Gibson RS. Primary school children from northeast Thailand are not at risk of selenium deficiency. Asia Pac J Clin Nutr 2006;15(4):474-481. https://www. ncbi.nlm.nih.gov/pubmed/17077062 (accessed July 4, 2013).

23. Jones CY, Tang AM, Forrester JE, et al. Micronutrient levels and HIV disease status in HIV-infected patients on highly active antiretroviral therapy 
in the nutrition for healthy living cohort. J Acquir Immune Defic Syndr 2006;43(4):475-482. https://doi.org/10.1097/01.qai.0000243096.27029.fe

24. Rousseau MC, Molines C, Moreau J, Delmont J. Influence of highly active antiretroviral therapy on micronutrient profiles in HIV-infected patients. Ann Nutr Metab 2000;44(5-6):212-216. https://doi.org/10.1159/000046686

25. Safaralizadeh R, Kardar GA, Pourpak Z, Moin M, Zare A, Teimourian S. Serum concentration of selenium in healthy individuals living in Tehran. Nutr J 2005;4:32. http://www.nutritionj.com/content/4/1/32 (accessed 13 May 2013).
26. Amare B, Tafess K, Ota F, et al. Serum concentration of selenium in diarrheic patients with and without HIV/AIDS in Gondar, Northwest Ethiopia. J AIDS Clin Res 2011;2:128. https://doi.org/10.4172/2155-6113.1000128

27. Nhien NV, Khan NC, Ninh NX, et al. Micronutrient deficiencies and anemia among preschool children in rural Vietnam. Asia Pac J Clin Nutr 2008:17(1):48-55.

28. Amare B, Moges B, Fantahun B, et al. Micronutrient levels and nutritional status of school children living in Northwest Ethiopia. Nutr J 2012;11:108. https://doi. org/10.1186/1475-2891-11-108 